\title{
A IDENTIDADE DO PROFESSOR LICENCIADO NO ENSINO MÉDIO INTEGRADO: ENTRE A PAIXÃO E O ACASO
}

\author{
W. E. A. DE M. LUSTOSA* e P. T. S. M. DA S. ALIANÇA** \\ Instituto Federal de Educação, Ciência e Tecnologia do Rio Grande de Norte \\ wigna.lustosa@ifrn.edu.br ${ }^{*}$ priscila.alianca@ifrn.edu.br ${ }^{* *}$
}

Artigo submetido em abril/2017 e aceito em maio/2017

DOI: $10.15628 /$ rbept.2017.5867

\section{RESUMO}

O presente artigo é parte da pesquisa desenvolvida na disciplina Formação de Professor para a Educação Profissional, intitulada "Licenciados, bacharéis e a formação docente para atuar na EPT: um estudo com docentes do curso de informática no IFRN". Nosso objetivo é compreender como se constitui a identidade docente de professores licenciados da educação profissional e tecnológica do ensino médio integrado à educação profissional do IFRN. As categorias de análise foram pensadas a partir das orientações de Bogdan e Biklen (1994). Para os autores, importa que as categorias emerjam da leitura do material coletado. Elegemos as três categorias mais recorrentes como aquelas que seriam abordadas neste estudo. Foram elas: percepção sobre a formação para a docência (27 ocorrências); relação prévia com a docência (16 ocorrências) e momentos-charneira (23 ocorrências). As três categorias trabalhadas aqui nos ajudam a compreender aspectos da identidade dos docentes entrevistados, cada uma deixando entrever os desenhos das tramas narradas. A primeira nos dá pistas sobre como cada professor relaciona sua própria formação e sua atuação profissional; a segunda nos indica os caminhos traçados antes da opção pela docência; a terceira nos permite confrontar esses caminhos anteriores e os hoje percorridos.

PALAVRAS-CHAVE: identidade docente, Educação Profissional, narrativa de si.

\section{THE IDENTITY OF INTEGRATED HIGHSCHOOL LICENSED PROFESSORS: BETWEEN PASSION AND CHANCE}

\begin{abstract}
This paper is part of the research developed during the Teacher Training for Vocational Education classes, named "Licensed teachers, unlicensed teachers and teacher training for Vocational Education: a study with IFRN professors in the Computer Technician course". We aim to understand how the licensed teacher's identity is constructed within the realms of Vocational Education in general and of IFRN in particular. The categories of analysis were conceived from the works of Bogdan and Biklen (1994). To these authors, it is important that the categories emerge from the corpus. The three categories
\end{abstract}

in this study are: perception of teacher training (27 occurrences); previous relationship with teaching (16 occurrences) and pivotal moments (23 occurrences). These categories help us understand aspects of the teacher's identity. The first category gives us leads about how each teacher relates their own academic studies to their work; the second points to the paths the teacher used to walk (before becoming a teacher); the third allows us to compare those paths to the ones the teacher walks in the present.

KEYWORDS: teacher identity, Vocational Education, self narrative. 


\title{
1 INTRODUÇÃO
}

O presente artigo é parte da pesquisa, desenvolvida na disciplina Formação de Professor para a Educação Profissional, intitulada "Licenciados, bacharéis e a formação docente para atuar na EPT: um estudo com docentes do curso de informática no IFRN". Nosso objetivo é compreender como se constitui a identidade docente de professores licenciados da educação profissional e tecnológica do ensino médio integrado à educação profissional do IFRN.

Essa pesquisa foi motivada por leituras e discussões em sala de aula que nos mostraram que os estudos sobre a formação de professores para atuar na Educação Profissional ainda são poucos, que há uma grande necessidade de uma formação direcionada para atuar nessa modalidade e que com a interiorização, e consequentemente a expansão dos Institutos Federais, se observou um aumento na demanda de professores com essa formação especifica.

Como categorias gerais da pesquisa da disciplina foram estabelecidas três: identidade docente, prática pedagógica e percepção sobre Educação Profissional. Aqui, nos debruçaremos somente sobre a categoria de análise identidade docente.

Essa é uma investigação de abordagem qualitativa e usaremos como instrumento de coleta de dados a entrevista semiestruturada. Nas palavras de Bauer e Gaskell:

\begin{abstract}
O emprego da entrevista qualitativa para mapear e compreender o mundo da vida dos respondentes é o ponto de entrada para o cientista social que introduz, então, esquemas interpretativos para compreender as narrativas dos atores em termos mais conceptuais e abstratos, muitas vezes em relação a outras observações. A entrevista qualitativa, pois, fornece os dados básicos para o desenvolvimento e a compreensão das relações entre os atores sociais e sua situação. O objetivo é uma compreensão detalhada das crenças, atitudes, valores e motivações, em relação aos comportamentos das pessoas em contextos sociais específicos. (BAUER; GASKELL, 2004, p. 65).
\end{abstract}

O objetivo real da pesquisa qualitativa não é o de escutar histórias e opiniões de pessoas, e sim o de explorar todas essas opiniões e histórias e suas diferentes representações sobre o tema abordado. Em um meio como o de nossa pesquisa, no âmbito da educação, o que estaremos centrados em descobrir serão os vários pontos de vistas em relação à formação e constituição da identidade docente, levando em consideração a peculiaridade de cada sujeito e sua história de vida. 
Segundo Bauer e Gaskell (2004, p. 70), “[...] o objetivo da pesquisa qualitativa é apresentar uma amostra do espectro dos pontos de vistas". Assim, com o corpus formado, buscaremos compreender como se manifestam as identidades docentes dos professores. Nosso corpus é constituído das transcrições de vinte e sete entrevistas realizadas em três campi distintos do IFRN, sendo dois situados na cidade de Natal (campus Natal-Central e campus Zona Norte) e um pertencente à região metropolitana da capital potiguar (campus Parnamirim). O campus Natal-Central é o mais antigo do Instituto, funcionando onde antes funcionaram o Centro Federal de Educação Tecnológica do RN (CEFET-RN), a Escola Técnica Federal do RN (ETFRN), e a Escola Industrial de Natal. Em 1994, foi criada a Unidade de Ensino Descentralizada de Mossoró. Pouco mais de uma década depois é que começou o que se convencionou chamar de expansão da rede federal de Educação Profissional e Tecnológica. O campus Zona Norte é fruto da chamada primeira fase da expansão, tendo sido estabelecido em 2006; já o campus Parnamirim foi criado na segunda fase, no ano de 2010. Estes dados históricos importam na medida em que nos ajudam a compreender um aspecto da ampla gama de relatos dos professores respondentes. Alguns só entraram como docentes no IFRN em 2015, enquanto outros iniciaram suas atividades ainda na ETFRN.

Um outro aspecto da amplitude nas respostas coletadas é a formação acadêmica inicial (a graduação). Como se sabe, mesmo no Ensino Médio Integrado (que constitui o recorte primordial para a seleção dos respondentes) os Institutos Federais têm em seus quadros professores sem formação docente inicial (bacharéis e tecnólogos), geralmente por um motivo simples e prático: não há licenciaturas para as chamadas disciplinas técnicas (aquelas da formação profissional específica). Já para as disciplinas propedêuticas, de formação geral, os professores em geral são licenciados (excetuando-se alguns professores que ingressaram antes da promulgação da Lei de Diretrizes e Bases da Educação Nacional (Lei 9.394 de 20 de dezembro de 1996, que estabelece a licenciatura como o espaço de formação do professor). Dados esses dois perfis básicos (professores licenciados e professores não-licenciados), temos mais um parâmetro a partir do qual observar as respostas das entrevistas.

O terceiro elemento a ser levado em conta na compreensão das entrevistas é a seleção de respondentes por núcleo. A Organização Didática do IFRN (2012, p. 16) estabelece, no seu Art. 35, a distribuição das disciplinas do Ensino Médio Integrado da seguinte forma:

Art. 35. A matriz curricular dos cursos técnicos de nível médio integrados regulares organizada em regime seriado anual, será constituída por 
disciplinas e estruturada em núcleos politécnicos, segundo a seguinte organização:

I. Núcleo estruturante: relativo a conhecimentos do Ensino Médio (Linguagens, Ciências Humanas, Ciências da Natureza e Matemática), contemplando conteúdos de base científica e cultural basilares para a formação humana integral;

II. Núcleo articulador: relativo a conhecimentos do Ensino Médio e da educação profissional, traduzidos em conteúdos de estreita articulação com o curso, por eixo tecnológico, representando elementos expressivos para a integração curricular. Contempla bases científicas gerais que alicerçam inventos e soluções tecnológicas, suportes de uso geral tais como tecnologias de informação e comunicação, tecnologias de organização, higiene e segurança no trabalho, noções básicas sobre o sistema da produção social e relações entre tecnologia, natureza, cultura, sociedade e trabalho. Configura-se, ainda, em disciplinas técnicas de articulação com o núcleo estruturante e/ou tecnológico (aprofundamento de base científica) e disciplinas âncoras para práticas interdisciplinares;

III. Núcleo tecnológico: relativo a conhecimentos da formação técnica específica, de acordo com o campo de conhecimentos do eixo tecnológico, com a atuação profissional e as regulamentações do exercício da profissão. Deve contemplar outras disciplinas técnicas não contempladas no núcleo articulador.

Desta forma, podemos traçar, como um panorama geral, a seguinte distribuição: professores predominantemente licenciados no núcleo estruturante; professores predominantemente bacharéis e tecnólogos no núcleo tecnológico; presença de professores com as três formações no núcleo articulador. Buscando conferir representatividade ao corpus, o grupo de trabalho da disciplina decidiu entrevistar três professores por núcleo. Como a pesquisa seria feita em três campi, chegamos ao total de vinte e sete respondentes. Para o estudo, estabelecemos categorias de análise para a identidade docente dos professores participantes.

As categorias de análise foram pensadas a partir das orientações de Bogdan e Biklen (1994). Para os autores, importa que as categorias emerjam da leitura do material coletado:

À medida que vai lendo os dados, repetem-se ou destacam-se certas palavras, frases, padrões de comportamento, formas dos sujeitos pensarem e acontecimentos. O desenvolvimento de um sistema de codificação envolve vários passos: percorre os seus dados à procura de regularidades e padrões, bem como de tópicos presentes nos dados e, em seguida, escreve palavras e frases que representam esses mesmos tópicos presentes nos dados e, em seguida, escreve palavras e frases que representam esses mesmos tópicos e padrões. Estas palavras são categorias de codificação. (BOGDAN E BIKLEN, 1994, p. 221) 
Fizemos as devidas adaptações ao passo-a-passo sugerido (BOGDAN E BIKLEN, 1994, pp. 233-238) e procedemos da seguinte forma:

a. Realizamos a leitura preliminar de todo o material, com o objetivo de iniciarmos nossa aproximação dele após um curto período de distanciamento da atividade de coleta;

b. Relemos o material completo buscando elencar categorias preliminares referentes à identidade docente a partir das transcrições;

c. Reelaboramos e condensamos as categorias preliminares mais relevantes (ou seja, aqueles tópicos de maior incidência);

d. Atribuímos a cada nova categoria uma cor como etiqueta e iniciamos o processo de marcação do material, bem como o levantamento das ocorrências das categorias por núcleo e por campus. Elegemos, finalmente, as três categorias mais recorrentes como aquelas que seriam abordadas neste estudo. Foram elas: percepção sobre a formação para a docência (27 ocorrências); relação prévia com a docência (16 ocorrências) e momentos-charneira (23 ocorrências).

O estudo preliminar do corpus sinalizou a necessidade de uma pesquisa bibliográfica que amparasse nossa análise em termos da constituição da identidade docente. Nossa pesquisa nos levou aos escritos de Zygmunt Bauman (2005), Marie-Christine Josso (2012), Paulo Freire (1983), Maria Madalena Araújo (2013) e António Nóvoa (1995), dentre outros, escritos aos quais nos reportaremos a seguir.

\section{A IDENTIDADE DOCENTE}

Os estudos sobre identidade docente no âmbito da educação vêm sugerindo alternativas para construir conhecimentos acerca do processo formativo de professores. É nos dias de hoje um tema debatido em diversas áreas, como por exemplo, na Sociologia, Antropologia, Filosofia e Educação. “Há apenas algumas décadas, a 'identidade' não estava nem perto do centro do nosso debate, permanecendo unicamente um objeto de meditação filosófica. Atualmente, no entanto, a 'identidade' é o 'papo do momento', um assunto de extrema importância e em evidência" (BAUMAN, 2005, p. 22). 
Interessa-nos aqui direcionar nossa discussão aos aspectos que evidenciam a questão da identidade, fazendo-nos compreender a formação docente através de questionamentos como: o que o tornou professor? Que caminhos de vida o levaram à docência? O que pensa sobre sua formação? Como se enxerga professor? Para isso, daremos vozes aos sujeitos para compreender um pouco de sua trajetória de vida pessoal e a cruzaremos com a trajetória profissional, no intuito de compreender o processo de formação dos professores.

A identidade docente é uma mescla da composição social, pessoal e cognitiva. Ela permeia a vida pessoal, a formação e a atuação do professor, a fim de assumir uma configuração própria do sujeito. A formação da identidade do professor é bastante influenciada pela maneira como ele se vê e se sente no processo. Dessa forma, ele consegue enxergar como se construiu enquanto docente, que professor foi, que professor é e como ele quer ser, se tornar. Como afirma Bauman (2005, p.17), “[...] a 'identidade' não tem a solidez de uma rocha”, ela pode modificar-se de acordo com o que o sujeito escolhe como caminho, que decisões toma e como se comporta diante das situações.

Pode ocorrer de a construção da identidade docente nascer através da influência de terceiros, estar atrelada a influencias externas, como família, amigos, professores ou experiências vividas, ou simplesmente ser sua própria escolha, ser aquilo em que quer se tornar. Bauman (2005, p.19) nos alerta para isso quando diz que "as 'identidades' flutuam no ar, algumas de nossa própria escolha, mas outras infladas e lançadas pelas pessoas em nossa volta, e é preciso estar em alerta constante para defender as primeiras em relação às últimas".

A importância de conhecer-se, de olhar para dentro de si no âmbito da formação docente não contribui somente com a compreensão que temos do nosso processo formativo e de como nos transformamos à medida que vivenciamos experiências, mas também permite que façamos inscrições de nós mesmos, que enxerguemos nosso itinerário formativo, o que buscamos e alcançamos na vida, fazendo com que cruzemos nossa trajetória acadêmica à profissional. Esse não é nosso objetivo nesse trabalho, mas a abordagem (auto)biográfica possibilita um aprofundamento nas questões de identidades docentes, pois, através de como o professor se narra, identificamos esses traços em suas histórias de vida e formação. Portanto, é inevitável recorrermos a leituras que tratem sobre esse aporte teórico-metodológico.

Quando narramos uma história sobre nós, recorremos à memória para a construção dessa narrativa. Poderíamos dizer, então, que a narrativa está para a memória, assim como a memória 
está para nosso passado. Fazendo esse resgate sobre histórias de si, é possível ver a presença de um universal singular, onde o ser falará sobre seu singular, que sai de um universo e está carregado de aspectos de uma sociedade.

Josso (2010) usa a metáfora do território para materializar as narrativas de vida e formação docente que são carregadas de experiências que colaboram, modificam e formam a identidade docente. Ela diz que por vezes esses territórios podem ser tangíveis ou intangíveis, estão sempre em evolução e evocam outros territórios, outras experiências, o coletivo, para poder representar o individual. "É por isso que a questão da identidade reflete sempre uma dimensão subjacente a categorias sociológicas em favor de uma antropologia fundamental que observa, apresenta, narra: a existencialidade singular-plural (JOSSO, 2010, p. 66)”. A análise das entrevistas dos 27 professores envolvidos na pesquisa permite trabalhar as questões identitárias de cada um, considerando a pluralidade do conjunto, as debilidades e submissão desses aspectos.

A formação não se constrói por acumulação (de cursos, de conhecimentos ou de técnicas), mas sim através de um trabalho de reflexividade crítica sobre as práticas e de (re) construção permanente de uma identidade pessoal. Por isso é tão importante investir a pessoa e dar um estatuto ao saber experiência [...] A formação passa por processos de investigação, diretamente articulados com as práticas educativas. (NÓVOA, 1995, p. 26 e 28).

Levando em consideração o que diz o autor e concordando com sua reflexão sobre a formação, não separamos o ser do fazer, o indivíduo da sua prática docente. A formação está relacionada a toda a vida acadêmica e pessoal desse professor e isso corresponde à sua identidade enquanto professor. Certos aspectos individuais da formação muitas vezes não são levados em conta, e através do estudo que pretendemos desenvolver, daremos ênfase ao cruzamento de aspectos pessoais e de formação como um todo, já que não tem como não considerar a trajetória de vida do docente quando analisamos seu processo formativo. Araujo nos diz que:

Assim, as experiências formadoras são construídas a partir daquilo que cada um experenciou enquanto ser social, ou pelos vínculos estabelecidos com a família, as histórias e sentimentos narrando as lembranças escolares, e que ao serem resgatadas no baú de memórias simbolizam fortes marcas no processo de formação do sujeito, com grandes implicações no seu fazer docente. (ARAUJO, 2012, p. 111). 
Essas experiências vivenciadas na formação enquanto ser social se constituem como identificações que deixam marcas no processo formativo, e daí não podermos falar de uma identidade docente livre de aspectos coletivos e individuais do sujeito. Para Pimenta (2007, p.19),

Uma identidade profissional se constrói, pois, a partir da significação social da profissão; da revisão constante dos significados sociais da profissão; da revisão das tradições. [...] Constrói-se, também, pelo significado que cada professor, enquanto ator e autor, confere à atividade docente no seu cotidiano a partir de seus valores, de seu modo de situarse no mundo, de sua história de vida, de suas representações, de seus saberes, de suas angústias e anseios, do sentido que tem em sua vida o ser professor. Assim como a partir de sua rede de relações com outros professores, nas escolas, nos sindicatos e em outros agrupamentos.

Podemos identificar, no âmbito da identidade docente, que existem aspectos positivos e negativos que marcam a trajetória formativa dos professores. Salgado e Antezana $(2013$, p. 27) já discutem que momentos singulares e chave na formação dos sujeitos direcionam para uma identidade positiva, que é percebida pelo desejo de saber do professor, de querer qualificar-se, renovar seu ensino, de contribuir para a formação dos alunos e de acreditar que seu trabalho pode cooperar para mudanças na sociedade.

[...] Tanto en el ingreso como en el posterior desempeño se configuran rasgos de una identidad atribuida que se nutre de atributos impuestos desde fuera con imágenes y representaciones sociales de la profesión con discursos y prácticas normativas que orientan la labor de los maestros y mediante directrices que delimitan actividades, formas de relación pedagógica, competencias y atributos orientados a la definición de un profesional de la docencia. (SALGADO; ANTEZANA, 2013, p. 30)

Assim como podemos identificar aspectos negativos sobre o exercício da docência, que são percebidos através de uma identidade atribuída, cheia de formas, de aceitação de funções e tarefas estabelecidas e que não são opções dos sujeitos.

Los primeros años del ejercicio docente pueden ser para los maestros un período de repliegue hacia experiencias previas vividas como estudiantes y a su vez un espacio para aprender a ser profesores desde nuevas experiencias. En el momento de su inserción los maestros se enfrentan a una realidad que los obliga a desarrollar estrategias para incluirse en el mundo profesional y lograr posicionarse como profesores en el sistema escolar. (SALGADO; ANTEZANA, 2013, p. 31) 
O primeiro contato com a docência, sua inserção no mundo do trabalho e o que isso representa, são aspectos chave para delimitar a identidade profissional docente. Esse momento é de extrema relevância, pois consegue deixar o docente diante de uma situação real da profissão, podendo transformar-se em desilusão ou amor profundo pelo oficio de professor. Para alguns, essa experiência pode ser representada como um aspecto positivo para a constituição da sua identidade docente, assim como o contrário é verdade. O sentido negativo dessa experiência pode ser atribuído aos conflitos do cotidiano, ao planejamento de aulas e a busca do que é para ele ser docente.

A questão das experiências terem ou não um sentido positivo para a identidade docente assumida pelo professor é extremamente importante para uma formação, seja ela inicial ou contínua, comprometida com a transformação, com a aprendizagem dos alunos, com a prática docente diária, com a responsabilidade e a eficácia da profissão. "As experiências que favorecem uma imagem positiva com a profissão ocorrem quando os professores conseguem encontrar pontes que confirmam o alcance do "desejo" de ser docente consigo mesmo e com os outros, assim como com sua formação como projeto de vida. (SALGADO; ANTEZANA, 2013, p. 36, tradução nossa)

Não há, portanto, como falar de identidade docente sem discutir a formação dos sujeitos. Essa formação, que entendemos assim como Pimenta (2007), que é autoformação, já que os docentes confrontam suas experiências com os saberes teóricos e práticos adquiridos no processo formativo. Ser um professor com atitudes reflexivas em relação à sua prática é essencial para torná-lo capaz de enfrentar os desafios, as inseguranças e a complexidade que giram em torno da educação, dos espaços escolares e da sociedade, e isso é algo que é internalizado no seu processo formativo, se constituindo com um aspecto positivo para a identidade docente. "A formação de professores reflexivos compreende um projeto humano emancipatório (PIMENTA, 2007, p. 31)".

\begin{abstract}
A história de vida narrada é assim uma mediação do conhecimento de si, em sua existencialidade, o qual oferece à reflexão de seu autor oportunidades de tomada de consciência sobre seus diferentes registros de expressão e de representações de si, assim como sobre as dinâmicas que orientam sua formação. (JOSSO, 2010, p. 69)
\end{abstract}

O processo de reflexão a partir do relato da história de vida e formação dos professores contribui para a percepção das mudanças sociais e culturais representadas em vidas singulares, 
que pertencem ao coletivo, ao plural, e que se relacionam a âmbitos da vida profissional e em sociedade.

Paulo Freire (1983) discute que o homem é um ser inacabado e que por isso a educação se torna possível para ele. Isso nos faz refletir como o processo formativo é algo continuo, que se recicla e se reestabelece de acordo com mudanças e necessidades. Assim também o é a formação da identidade docente, que "deve ser constituída sob conteúdos que extrapolem o já cristalizado para a prática docente e fundar-se na ética, no respeito à dignidade e na autonomia do educando, no compromisso como práxis (ação e reflexão da realidade), carregada de humanismo e fundada cientificamente" (SILVA, MURARO, 2012, p. 7).

\section{ANÁLISE DAS ENTREVISTAS}

Tendo em vista a relevância da narrativa de si para a constituição e compreensão da identidade subjetiva, buscamos compreender a identidade docente a partir de seus relatos sobre a docência. Afinal, essa identidade não se resume à formação ou à titulação: a identidade docente é entretecida pelos fios da história pessoal, acadêmica e profissional, perpassada por vieses afetivos e relativos à realidade objetiva, à necessidade de produção da própria existência. A narrativa é esse tear em que o sujeito tece sua história e deixa entrever sua identidade na trama. Assim cada categoria remete a uma configuração que vai surgindo no tecido.

A primeira categoria analisada foi percepção sobre a formação para a docência. Como uma das perguntas no roteiro das entrevistas era bem direta ("Você considera necessária uma formação específica para ser docente?"), todos os vinte e sete respondentes se manifestaram a respeito.

Um dado que nos chamou a atenção diante das respostas foi a presença de um sentimento dual em relação à formação docente inicial (licenciatura). A maioria dos professores (dezesseis, precisamente) foram categóricos em dizer que sim, que era necessária uma formação inicial para a docência; apenas um professor, no entanto, foi firme em dizer que não. Ora, como então se posicionam os outros dez?

A dualidade a que nos referimos diz respeito a uma modalização no discurso do respondente no momento em que ele responde à pergunta em questão aqui. São respostas que se iniciam com uma negação, mas em algum momento concordam; ou então são respostas que começam concordando, mas mudam de perspectiva; uma terceira vertente é representada por 
sujeitos que tecem comentários a respeito da (falta de) formação docente inicial, mas em nenhum momento deixam claro se a consideram ou não necessária.

Seguem algumas respostas que ilustram essa dualidade. Grifamos os trechos que contradizem o posicionamento inicial:

“Bom, talvez não seja necessário tá mas... quando você tem esse conhecimento Ihe facilita muito, né, o seu desenvolvimento em sala de aula. Então eu acredito que é... é imprescindível, é importante sim."

"Eu acho que uma formação específica vai contribuir, mas ela, pra mim ela não é um pré-requisito obrigatório, eu acho que não é obrigatório, mas certamente deve contribuir. [...] Por não ter essa formação específica da licenciatura, eu não me considero incapaz, ou menos habilitado em certos aspectos do que um licenciado, mas certamente existem experiências e conhecimentos que devem contribuir, sim, nesse sentido, eu acho que sim. [...] provável deficiência que os não licenciados, os bacharéis, têm. Qual é essa provável deficiência? Eu confesso que eu não sei bem isso, eu não sei."

"Veja bem... é complexo isso, é complexo. Porque também tem essa questão da vocação, que mesmo quem não faz licenciatura... quem faz licenciatura pode ir muito bem, como eu, e não ter a vocação pra docência. E também tem aquelas pessoas que não fazem e tem vocação, né? [...] Mas, eu não sei. Acho que, talvez, acho que sim, sim, respondendo a pergunta de forma objetiva, sim."

O curioso nesses depoimentos é que os entrevistados parecem construir seu posicionamento no momento em que são questionados a respeito da (falta de) necessidade da licenciatura para o professor. É o dizer-se que constitui a realidade de cada um. Esse fenômeno condiz perfeitamente com um dos princípios enumerados por Passeggi (2011, pp. 20-21) para o trabalho com narrativas de si, que é a "construção da realidade mediante a linguagem pelo sujeito ou pelo grupo". Concordando com a autora, Aliança $(2014$, p. 1) esclarece que a “linguagem (escrita ou oral) não é apenas um meio de se conhecer a realidade; é antes um elemento constitutivo da realidade. Entende-se, então, que não há uma história até que ela seja narrada". Verificamos, portanto, que para esses sujeitos que têm um posicionamento ambivalente a respeito do tema em pauta o momento da entrevista foi um momento de reflexão e construção desse posicionamento.

Algumas das respostas de professores licenciados indicam que eles reconhecem o mérito de sua formação inicial, mas parecem não querer desmerecer a atuação de seus colegas 
bacharéis e tecnólogos - cuja prática reconhecem como relevante e bem conduzida - como nos trechos abaixo:

\begin{abstract}
"Eu acho que é fundamental você dar uma formação mais específica mas eu também acho que tem muitas pessoas que não tiveram a formação específica e que têm aquele feeling, também, aquela sensibilidade para poder também estar desenvolvendo."

“Sim. É até questão de respeito. Eu só respeito, sério mesmo, uma pessoa que tenha licenciatura, para dar aulas. Não no curso técnico, eu respeito um engenheiro que dá aula em curso técnico, pois ele tem a prática dele, mas eu acho que a pessoa tem que ter formação. É evidente."
\end{abstract}

Já algumas respostas de professores não licenciados sinalizam o caminho inverso. Como eles se reconhecem como professores mesmo não tendo a "licença", eles tendem a atribuir a capacitação para a docência a uma força cujo controle lhes escapa (vocação, gosto, vontade, destino); entretanto, não desejam desconsiderar aqueles colegas que, ao contrário, dedicaram anos de suas vidas à formação específica para a profissão docente. Até porque, em muitos casos, esses colegas licenciados eram os próprios entrevistadores. Então, esses entrevistados defendem a importância de alguma formação (não necessariamente a licenciatura), recorrendo inclusive a processos formativos pelos quais eles mesmos passaram ou à falta que esses processos formativos fazem:

"Eu não tive, mas eu sinto falta, e olhe que eu venho dessa área de humanas e eu ainda tenho um pouquinho de traquejo com algumas questões, mas eu acho que é bastante necessário."

“É... por ser da área técnica, por estar na área onde se tem muito engenheiro, bacharel, eu acredito que, para lecionar, sim, é necessário. Pelo menos alguma preparação, um curso. Apesar de considerar também que dar aula é um dom."

"Não, eu acho que não precisa ser não, agora algumas situações de sala de aula, se eu não tivesse feito esse curso talvez eu tivesse dificuldade."

Quanto às respostas que concordaram com a necessidade de formação específica para a docência, nós podemos perceber que a concordância acontece em dois eixos distintos, porém complementares: um eixo pragmático e outro político. Os respondentes representados abaixo percebem uma dimensão pragmática muito clara e objetiva a respeito da formação docente: 
"É, eu acredito que sim, porque você dar aula, você tratar com... você quando é técnico, você formado em outro nível, mesmo técnico, técnico, você trabalha com equipamento, você não trabalha com pessoas, entendeu?"

"Com certeza. [...] Eu acho que precisa, eu acho não, tenho certeza de que precisa. Existem várias disciplinas, várias cadeiras que são importantes. Mesmo eu tendo dito que a qualidade não era o que eu pensava, mas tem coisas, tem professores, teve leituras que foram importantes para a minha formação profissional. [incompreensível] docente... O próprio estágio - eu não, eu tô, vamos dizer assim, na vantagem de ter tido esse contato, mas tem gente que não tem. Tem tipo um estágio mesmo. Então se não tiver, como é que a pessoa vai saber?"

O professor acredita ser necessário uma formação específica para a docência, uma vez que ela ajuda os futuros professores a entenderem melhor os alunos, a prática pedagógica e outras questões referentes à educação e à sala de aula. ${ }^{1}$

"Eu tenho certeza absoluta... eu não tinha condição de dar aula não tinha nenhuma condição de dar aula, eu tinha condição de ministrar, digamos assim cursos curtos. Aula eu não tinha..."

O eixo político revela que muitos professores reconhecem a necessidade de formação não apenas por questões práticas, mas por outras questões relativas, inclusive, ao debate da profissionalização docente:

"Todo mundo é professor, todo mundo fala sobre profissão de professor, todo mundo mete o bedelho onde não deve, enfim... Aí, é um complicador, porque, todo mundo faz cirurgia? Todo mundo constrói casa? Eles têm saberes específicos, nós temos também."

"Acredito. Acredito sim, apesar de não acreditar nesse mantra da vocação né, contradiz isso que falei aqui agora, no sentido de que isso muitas vezes funciona politicamente para esmagar a gente, né..."

"Acho, eu acho importante, eu acho importante. A gente sente um pouco a diferença na discussão, na fala desses professores que não têm uma formação... de licenciatura... uma forma mais, talvez, um olhar diferente, uma postura diferente. Um tratar diferente."

"Não é só assim, 'tem a formação, quem quiser... Quem não quiser, beleza.' Mas, a gente não tem que se especializar? Então, não é quem

\footnotetext{
${ }^{1}$ Este respondente em particular não permitiu que sua entrevista fosse gravada. Por isso suas respostas estão registradas em discurso indireto.
} 
quiser. É uma obrigação. É questão de ética. Cada um tem que entender que tá nesse âmbito, tem que aprender sobre isso."

A segunda categoria analisada foi relação prévia com a docência. Ela diz respeito a como os respondentes se relacionavam com a ideia da docência antes de optarem definitivamente por ela. Boa parte dos respondentes não se manifestou a esse respeito. Das dezesseis ocorrências, oito se referem a uma relação positiva (como, por exemplo, sujeitos que foram monitores na universidade ou que gostavam de ensinar seus colegas), três a uma relação negativa (sujeitos que queriam seguir qualquer profissão, exceto a docente, até a ocorrência de um momento-charneira - um evento caracterizado como um "divisor de águas" - que os fizesse mudar o rumo), seis não manifestam nem gosto nem repulsa e uma ocorrência diz respeito a uma respondente que tinha uma relação positiva que depois se tornou negativa.

Num primeiro instante pode parecer que as experiências positivas dizem respeito aos licenciados e as demais aos não-licenciados. Entretanto, isso não se confirma. Os relatos abaixo são de professores com licenciatura:

"É, até a graduação eu não tinha esse pensamento não, inclusive eu corria. Corria léguas disso."

"Quando eu ainda fazia o bacharelado eu não me via de modo algum como professor. Eu sempre achava que ser professor exigia uma habilidade, uma competência de comunicação, de ser capaz de se expor e falar, uma competência que eu não tinha e jamais me imaginava tendo isso. [...] E no fim do bacharelado ainda não me via atuando como professor, nem me imaginava, mas assim que eu concluí o bacharelado eu senti vontade de fazer o reingresso na licenciatura, era uma opção viável, com pouca burocracia, na UFRN. Eu fui, fiz o reingresso para continuar a estudar, continuar em contato com as ciências sociais."

"Depois é que veio o interesse de migrar mesmo para a educação física como componente curricular."

"Quando eu fiz Filosofia eu não fiz pensando nisso não."

[O respondente] não queria de nenhuma maneira ser professor.

O primeiro trecho e o segundo são de respondentes que ingressaram num dado bacharelado antes de migrare $\mathrm{m}$ para a licenciatura. Percebemos que no primeiro há explicitamente um compromisso com a ideia de não considerar a docência como possível 
profissão. O segundo traz também um pouco disso, mas de uma maneira mais cuidadosa e reflexiva. O que afasta o respondente não é uma repulsa pela atividade docente, mas antes um senso de responsabilidade tamanho que ele não se via à altura do desafio de ser professor.

O terceiro excerto é de um respondente que ingressou na licenciatura em Educação Física com o intuito de trabalhar com esportes, em vez de trabalhar propriamente na Educação Básica. Em algum momento durante sua trajetória formativa sua perspectiva mudou. Assim como o autor do quarto relato, ele não deixa claro se ingressou diretamente na licenciatura ou se começou no bacharelado. Já o último trecho fala de um respondente que queria, na verdade, ser dentista, mas nunca professor. De qualquer forma, fica claro que professores licenciados, assim como os não-licenciados, passam por momentos em que a docência não figura entre seus sonhos profissionais.

Seguem agora trechos de respondentes bacharéis e/ou tecnólogos para quem a docência foi sempre vista com bons olhos:

"Minha mãe e meu pai são professores e eu fui educado muito nisso."

"Eu sempre gostei de ajudar, eu sempre era monitor quando era aluno das disciplinas. Pra mim aquilo era voluntário e prazerosa essa ideia. Pois passava conhecimento e aprendia, né, o natural do processo."

"Ó, na verdade, assim, eu sempre quis ser professor. Uma das áreas que eu queria seguir era a área de Matemática. Mas, pela influência da escola, da família... eu não queria usar a palavra que eu não fui permitido fazer matemática, mas eu fui orientado a fazer também uma coisa que eu gostava na época, que era informática."

O primeiro trecho revela um respondente que tinha uma relação positiva com a docência mesmo antes dela se tornar uma possibilidade profissional, por causa do convívio familiar. 0 segundo também se via bastante confortável desempenhando atividades que ele atribui à rotina docente - aqui não se trata de influência externa, mas de um caminho de autodescoberta. Já o terceiro se destaca bastante pela peculiaridade do narrado. O respondente tivera, desde sempre, o anseio de se tornar professor. Tinha inclusive uma área do conhecimento favorita na qual ele gostaria de atuar. Entretanto, o que inferimos é que elementos externos ("influência da escola, da família") advertiram o respondente contra a busca desse alvo. O próprio respondente diz "eu não queria usar a palavra que eu não fui permitido fazer matemática" - ou seja, em algum nível 
foi exatamente o que ele sentiu - que não lhe seria permitido ser professor de matemática. Migrou para a área de TI, que também Ihe agradava.

A terceira e última categoria analisada aqui é momentos-charneira. Um momento charneira, ou momento-dobradiça, é constituído, segundo Josso (2010), por um acontecimento ou uma experiência a partir da qual a história de vida do indivíduo toma um rumo diferente do que vinha tomando, um "divisor de águas". Interessa-nos, portanto, compreender como a trajetória profissional do sujeito sai do curso anterior e se redireciona rumo à docência. Esta categoria vem após relação prévia com a docência porque queremos justamente mostrar em que momento a ideia da docência foi transformada ou consolidada nas vidas dos respondentes.

A leitura atenta das transcrições nos permitiu identificar três eixos gerais dentro desta categoria. O primeiro, com maior número de ocorrências (nove, de vinte e duas), abarca os momentos-charneira em que a decisão pela docência foi tomada, predominantemente, por motivações afetivas ${ }^{2}$. No segundo, com menos ocorrências (cinco), estão as decisões em que pesaram mais os fatores objetivos. O terceiro, com o segundo maior número de ocorrências (sete), revela um dado curioso. Estão neste eixo aqueles relatos segundo os quais a opção pela docência não foi exatamente uma decisão refletida, pensada, elaborada. Ela "foi acontecendo". O respondente, por vezes, se aproximou da docência por uma oportunidade que surgiu sem que ele procurasse. Há relatos segundo os quais a docência escolheu o respondente, numa perspectiva coerente com a ideia de vocação. Um respondente relatou um processo tanto afetivo quanto "involuntário", digamos assim.

Seguem alguns trechos do primeiro eixo (motivações afetivas):

"Resumindo, o que me motivou foi, primeiro, as olimpíadas de matemática, a paixão pela disciplina; e também pelo fato de admirar a prática de professores, não só o professor Fulano, mas em todo meu desenrolar eu sempre fui observador, e tive várias práticas que me deixaram motivados, onde pensei 'é isso que eu quero pra minha vida, é dar aula'."

“[...] ela perguntou 'Ô, Fulano', a gente tá precisando de professor de geografia, você quer ter essa experiência?' E ela... eu gostei da oportunidade de lecionar. E eu já nesse contato - era bem imaturo mesmo, devia ter 20 anos, 21 anos de idade, mas eu já notei que era o que eu queria ser mesmo, professor, me identifiquei muito. E quando eu

\footnotetext{
${ }^{2}$ Entendemos que o afeto perpassa toda ação humana. Aqui a distinção é feita entre uma prevalência de aspectos afetivos na narrativa do respondente. Ou seja, na medida em que ele ou ela (se) conta.

${ }^{3}$ Os nomes citados foram trocados pelo termo Fulano para evitar a identificação dos respondentes.
} 
decidi sair da UFRN pra UERN, fazer o convênio entre as duas faculdades... eu pensei 'no vestibular não vou fazer Geografia não, vou fazer Direito'. Mas nesse meio tempo, esse 'olha, vamos ensinar lá na minha escola'. Aí eu vi que realmente geografia era a minha área. Aí eu falei "não, vou fazer geografia de novo". E aí fiz Geografia e pronto, me formei."

"E aí, no mestrado, né, tem aquela atividade que é estágio de docência. Foi nela que realmente despertou. Quando eu entrei numa turma grande para dar aula de engenharia de computação... eu gostei."

O primeiro relato revela um caminho direcionado para a docência desde a Educação Básica. A paixão por uma determinada área do conhecimento se aliou à inspiração advinda da prática de bons professores, professores marcantes. Já o segundo trecho é de um respondente que tinha uma certa inclinação para o estudo de geografia e pensou em se tornar professor, mas ainda titubeava mesmo dentro da licenciatura. Tanto que cogitou a possibilidade de deixar a licenciatura em geografia pelo bacharelado em direito. O que o impediu de seguir nesse plano foi a primeira experiência vivida como professor. O prazer advindo da prática de sala de aula foi determinante para que o respondente fizesse da docência sua profissão, definitivamente. Por sua vez, o terceiro depoimento foi dado por um respondente que foi seduzido pela atividade docente já na pós-graduação. Esse é provavelmente um dos fatores pelos quais ele não cursou uma licenciatura: quando a docência se lhe apresentou, o respondente já era bacharel e buscava a verticalização dos estudos - não cabendo nos seus planos de vida o retorno a uma graduação.

O segundo eixo (prevalência dos aspectos objetivos) será representado pelos seguintes trechos:

\footnotetext{
"Quando eu voltei [de uma viagem de estudos ao exterior], prestei a prova do concurso do Instituto Federal e desde 2011.2 que eu sou professor do Instituto."
}

Porém, resolveu mudar e cursar a licenciatura em matemática, nesse momento já dava aulas particulares para amigos.

“'Ó, vamos fazer o seguinte: a gente tenta uma vaga no Rio grande do Norte pra ser professor de redes, alguma coisa assim.'”

O primeiro trecho revela que a opção pela docência aconteceu de maneira pragmática. Pelo relato, o respondente demonstra ter prestado o concurso para o IFRN com a ideia de produzir a própria existência, de assumir um dado posto de trabalho - que calhou de ser no 
serviço público e na docência. O segundo é de um respondente que não gostaria de ser professor, mas sim dentista. Entretanto, com a alta concorrência do exame vestibular para odontologia, este sujeito decidiu cursar um bacharelado numa área do conhecimento para a qual tinha aptidão - aptidão essa apontada ainda na Educação Básica por um professor. Diante da necessidade de conseguir seu sustento, acontece, finalmente, a "opção" pela docência. Esta foi a alternativa que suas condições objetivas lhe impuseram. O terceiro trecho é de um professor que residia em outro estado e trabalhava na sua área de formação. Sua esposa passou num concurso público no Rio Grande do Norte e eles passaram a administrar o casamento à distância. Surgiu, então, o desejo de terem filhos: estarem juntos passou a ser o objetivo primordial. Surge, então, a possibilidade de concurso público para professor de redes. O respondente passou na prova e atua como docente desde então. Aqui, mesmo havendo um componente afetivo importantíssimo na mudança de direção profissional (o desejo da paternidade), a docência passa a ser um alvo a partir de condições objetivas (a necessidade de encontrar um emprego no Rio Grande do Norte).

Os professores que conferem suas trajetórias profissionais à vontade do acaso ou à vocação irresistível muitas vezes narram suas histórias de modo a suavizar os traços de sua passividade, atribuindo à sua opção pela docência um caráter de encantamento (no sentido de atribuir um fato a elementos "mágicos"):

"Acho que foi ela que me escolheu, na verdade, foi um... não foram tantas escolhas determinantes, né, da minha parte... eu terminei o mestrado, cursei graduação e mestrado numa sequência única e ao terminar o mestrado houve a possibilidade de um concurso para substituto lá na UFPB, né, e eu acabei passando nesse concurso."

"Bom, como na vida a gente não escolhe nada, né, a gente pensa que escolhe. Na verdade nós somos escolhidos. É... enquanto estudante, enquanto aluno, eu nunca tinha pensado em lecionar, muito pelo contrário, né... terminei minha faculdade e fui pra iniciativa privada. Então eu trabalhei muito tempo em uma multinacional e estava nessa multinacional quando surgiu esse concurso. Concomitantemente eu trabalhava na indústria e também comecei a dar aula no estado, num curso profissionalizante: estava faltando professor, então fizeram um contrato com professores; então foi daí que eu entrei na educação e... fui escolhida."

"É... penso que... vocação, mesmo. Vocação, gostar de... no caso a minha primeira licenciatura foi em educação física. Eu gostava muito de, né, gostava de exercícios, então foi interesse pelas práticas corporais." 
Percebemos, dentro mesmo dos trechos selecionados, a contradição entre o encantamento (que teria conduzido os sujeitos à sala de aula) e a narrativa subsequente, que revela claramente o aspecto objetivo da opção pela docência. No primeiro caso, o sujeito fez um concurso para ser docente universitário. Entretanto, a expressão com que ele narra o evento é "eu acabei passando nesse concurso", atribuindo um caráter aleatório ao acontecimento. A segunda narrativa vai numa direção semelhante. A decisão de aceitar o trabalho de professor coube ao respondente, que teve sim papel ativo no processo de se tornar docente. Uma escolha feita provavelmente com o intuito de ter um emprego, de se manter, uma escolha feita com critérios objetivos que aqui são omitidos. O sujeito narra sua chegada à profissão docente de maneira que pareça especial e mágica.

O mesmo acontece no último trecho, que apresenta um chamado sobrenatural ("vocação") como justificativa para sua opção pela docência. Este sujeito conta a seguir que optou pela licenciatura por causa das "práticas corporais"; mais adiante ele revela que foi para outra licenciatura motivado novamente pela área do conhecimento daquela licenciatura, não pelo desejo de ser professor. Avançando na sua narrativa, ele deixa claro que diante de sua formação, a docência era o caminho que as condições objetivas apontavam para que o sujeito pudesse produzir sua existência. Assim, observamos que nem todos os professores que optam pela docência por questões objetivas e sem muita reflexão se dão conta disso ou se sentem confortáveis com isso, de nodo que revestem sua trajetória de uma aura de encantamento.

Entretanto, isso não aconteceu com todos os respondentes, como se pode observar no trecho abaixo:

\footnotetext{
"Oportunidade. Oportunidade que surgiu. A partir do momento que eu comecei também a orientar os meus técnicos lá na empresa que eu trabalhava (e estagiários também, que tinha uns dois estagiários lá, de desenvolvimento de programação), assim, cada vez mais... eu tinha uma facilidade de orientá-los, coisas técnicas, e como surgiram oportunidades de lecionar... eu fui, abracei e tal... assim, desde então nunca mais saí, sempre teve uma oportunidade."
}

Este professor deixa muito claro que as oportunidades de trabalho na docência surgiam, por mais que ele não as buscasse diretamente, e ele se deixou levar por esses caminhos. Mais adiante em sua narrativa, o respondente afirma que, apesar de ser bastante apaixonado pela atividade profissional que desenvolvia anteriormente, optou pela docência definitivamente ao passar no concurso do IFRN. Não era sua escolha primordial, mas a mais conveniente. Também 
diz que gosta muito de ser professor e deixa entrever que se não gostasse não permaneceria no cargo. A docência surge, na narrativa deste respondente, como um elemento sedutor.

As três categorias trabalhadas aqui (percepção sobre a formação para a docência, relação prévia com a docência e momentos-charneira) nos ajudam a compreender aspectos da identidade dos docentes entrevistados, cada uma deixando entrever os desenhos das tramas narradas. A primeira nos dá pistas sobre como cada professor relaciona sua própria formação e sua atuação profissional; a segunda nos indica os caminhos traçados antes da opção pela docência; a terceira nos permite confrontar esses caminhos anteriores e os hoje percorridos.

\section{CONSIDERAÇÕES FINAIS}

A pesquisa sobre identidade docente na Educação Profissional tem muitas léguas a serem percorridas. Com a ampla gama de formação dos seus professores (licenciados, técnicos de nível superior, engenheiros, administradores de empresa, analistas de sistema, etc.), o desafio que se apresenta fica ainda maior.

Entendemos que o modelo das ciências sociais que requer um caráter nomotético, generalizante, não seja suficiente para compreender a constituição identitária de um grupo social tão diverso. Por isso trouxemos o trabalho com narrativas de si como aporte teórico e de metodologia. Por meio do recorte do plural manifesto no singular, cada narrativa permite a compreensão não apenas de si mesma, mas também do universo em que se dá. Apesar do método de coleta de dados não ter sido propriamente uma entrevista narrativa, entendemos que toda narrativa é uma narrativa de si. Toda narrativa nos revela seu narrador.

Um elemento bastante recorrente às narrativas analisadas é a ausência de planos de mudança profissional. À exceção de um, nenhum professor manifestou a possibilidade de deixar de ser professor. De alguma forma, por algum caminho, a docência seduziu esses sujeitos. Nessa sedução devem pesar muitos fatores de ordem objetiva e subjetiva. A estabilidade do serviço público, as condições de trabalho e o plano de carreira certamente contam; a valorização social do "professor do IF", o relacionamento com os alunos e colegas, a consciência de trabalhar para um bem social comum e a possibilidade de prosseguir estudando também. Tenham sonhado com a docência desde a infância, se apaixonado por ela já adultos ou aceitado a docência como um ganha-pão possível, esses professores se renderam ao ofício de professor, assumindo um relacionamento com ele até que a aposentadoria os separe. Tenha sido um casamento por amor ou por conveniência, entendemos, após este trabalho, que é um casamento feito para durar. 


\section{REFERÊNCIAS}

1. ALIANÇA, Priscila. De que lado mora a sua práxis? Conte sua história que eu vou lhe mostrar: o professor de Língua Inglesa entre o reacionário e o revolucionário. Anais do $\mathrm{VI}$ Ciclo de debates em Ciências Sociais - CESO, Seminário Internacional "Max Weber 150 Anos" e VII Colóquio Internacional de Ciências Sociais. Natal: UFRN, 2014. p. 270-281. Disponível em <https://drive.google.com/file/d/OB4e5IzhXHHCbVmNFWIFObVJyUnM/view>. Acesso em 22 abr. 2015.

2. ARAÚJO, Maria Madalena Mota de. Memória e formação de professores do campo: Histórias de vida de alunos da 'Especialização em educação do campo e desenvolvimento territorial do semiárido brasileiro' da UFRB (Turma I - 2011 - 2012). Entrelaçando: Revista Eletrônica de Culturas e Educação, Bahia, v. 2, n. 6, p.101-115, 2012. Disponível em: <http://www.ufrb.edu.br/revistaentrelacando/>. Acesso em: 27 mar. 2013.

3. SILVA, Sara; MURARO, Darcísio Natal. A busca pela formação da identidade docente: a autonomia em construção pela problematização, diálogo democracia. Disponível em: http://www.ucs.br/etc/conferencias/index.php/anpedsul/9anpedsul/paper/viewFile/274 1/568. Acesso em: 10 mar. 2015.

4. BAUER, Martin W.; GASKELL, George. Pesquisa qualitativa com texto, imagem e som: Um manual prático. 3a ed. Petrópolis, RJ: Editora Vozes, 2004. 516 p.

5. BAUMAN, Zygmunt. Identidade: Entrevista a Benedetto Vecchi. Rio de Janeiro: Jorge Zahar, 2005.

6. BOGDAN, Robert; BIKLEN, Sari. Investigação qualitativa em Educação. Porto: Porto Editora, 1994.

7. FREIRE, Paulo. Educação e Mudança. 11. ed. Rio de Janeiro: Paz e Terra, 1983.

8. IFRN/Instituto Federal do Rio Grande do Norte. Organização Didática do IFRN. Disponível em: <http://www.ifrn.edu.br/>. Natal/RN: IFRN, 2012.

9. JOSSO, Marie-Christine. Experiências de vida e formação. 2. ed. Natal: EDUFRN; São Paulo: Paulos, 2010.

10. NÓVOA, António. (Org.). Os professores e a sua formação. Lisboa, Portugal: Publicações Dom Quixote, 1995.

11. MINAYO, Maria Cecília de Souza. 0 desafio do conhecimento: pesquisa qualitativa em saúde. São Paulo: Hucitec, 2013.

12. PASSEGGI, Maria da Conceição. A pesquisa (auto)biográfica em educação: princípios epistemológicos, eixos e direcionamentos da investigação científica. In: VASCONCELOS, Fátima; ATEM, Érica. (Org.). ALTERidade: o outro como problema. Fortaleza: Expressão Gráfica, 2011, p. 13-39.

13. PIMENTA, Selma G.; Saberes pedagógicos e atividade docente. São Paulo: Cortez, 2007.

14. PIMENTA, Selma G.; ANASTASIOU, Léa das Graças C. Docência no ensino superior. 5. ed. São Paulo: Cortez, 2011.

15. SALGADO, María Adelina Castañeda; ANTEZANA, Cecilia Salomé Navia. Identidades docentes: experiencias y modos de identificación en la formación. In: VICENTINI, Paula Perin; SOUZA, Elizeu Clementino de; PASSEGGI, Maria da Conceição (Org.). Pesquisa (auto)biográfica: Questões de ensino e formação. Curitiba: CRV, 2013. p. 27-41. 